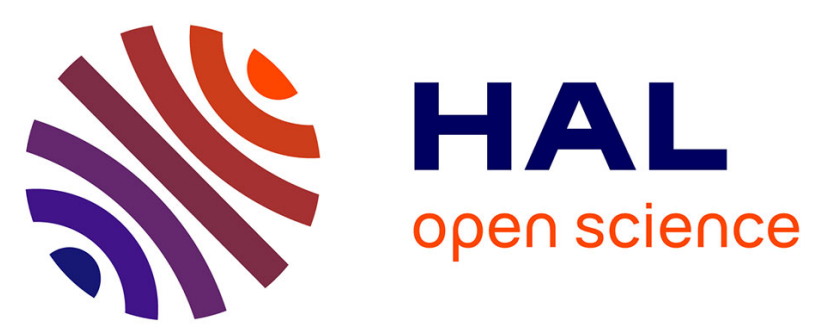

\title{
Alterations of 3D acetabular and lower limb parameters in adolescent idiopathic scoliosis
}

\author{
Mohammad Karam, Aren Joe Bizdikian, Nour Khalil, Ziad Bakouny, Ibrahim \\ Obeid, Joe Ghanimeh, Chris Labaki, Georges Mjaess, Aya Karam, Wafa \\ Skalli, et al.
}

\section{To cite this version:}

Mohammad Karam, Aren Joe Bizdikian, Nour Khalil, Ziad Bakouny, Ibrahim Obeid, et al.. Alterations of 3D acetabular and lower limb parameters in adolescent idiopathic scoliosis. European Spine Journal, 2020, 29 (8), pp.2010-2017. 10.1007/s00586-020-06397-5 . hal-02966707

\section{HAL Id: hal-02966707 https://hal.science/hal-02966707}

Submitted on 14 Oct 2020

HAL is a multi-disciplinary open access archive for the deposit and dissemination of scientific research documents, whether they are published or not. The documents may come from teaching and research institutions in France or abroad, or from public or private research centers.
L'archive ouverte pluridisciplinaire HAL, est destinée au dépôt et à la diffusion de documents scientifiques de niveau recherche, publiés ou non, émanant des établissements d'enseignement et de recherche français ou étrangers, des laboratoires publics ou privés. 


\title{
Alterations of 3D acetabular and lower limb parameters in adolescent idiopathic scoliosis
}

\author{
Mohammad Karam ${ }^{1} \cdot$ Aren Joe Bizdikian ${ }^{1} \cdot$ Nour Khalil $^{1} \cdot$ Ziad Bakouny $^{1} \cdot$ Ibrahim Obeid $^{2} \cdot$ Joe Ghanimeh $^{1}$. \\ Chris Labaki ${ }^{1} \cdot$ Georges Mjaess $^{1} \cdot$ Aya Karam $^{1} \cdot$ Wafa Skalli $^{3} \cdot$ Khalil Kharrat $^{1} \cdot$ Ismat Ghanem $^{1} \cdot$ Ayman Assi $^{1,3}$ (I)
}

\begin{abstract}
Purpose To evaluate the 3D deformity of the acetabula and lower limbs in subjects with adolescent idiopathic scoliosis (AIS) and their relationship with spino-pelvic alignment.

Methods Two hundred and seventy-four subjects with AIS (frontal Cobb: $33.5^{\circ} \pm 18^{\circ}\left[10^{\circ}-110^{\circ}\right]$ ) and 84 controls were enrolled. All subjects underwent full-body biplanar X-rays with subsequent 3D reconstructions. Classic spino-pelvic and lower limb parameters were collected as well as acetabular parameters: acetabular orientation in the 3 planes (tilt, anteversion and abduction), center-edge angle (CEA) and anterior and posterior sector angles. Subjects with AIS were represented by both lower limb sides and classified by elevated (ES) or lowered (LS), depending on the frontal pelvic obliquity. Parameters were then compared between groups. Determinants of acetabular and lower limb alterations were investigated among spino-pelvic parameters.

Results Acetabular abduction was higher on the ES in AIS $\left(59.2^{\circ} \pm 6^{\circ}\right)$ when compared to both $\operatorname{LS}\left(55.6^{\circ} \pm 6^{\circ}\right)$ and controls $\left(57.5^{\circ} \pm 3.9^{\circ}, p<0.001\right)$. CEA and acetabular anteversion were higher on the LS in AIS $\left(32^{\circ} \pm 6.1^{\circ}, 20.5^{\circ} \pm 5.7^{\circ}\right)$ when compared to both ES $\left(28.7^{\circ} \pm 5.1^{\circ}, 19.8^{\circ} \pm 5.1^{\circ}\right)$ and controls $\left(29.8^{\circ} \pm 4.8^{\circ}, 19.1^{\circ} \pm 4^{\circ}\right.$, respectively, $\left.p<0.001\right)$. Anterior sector angle was lower on both ES and LS in AIS when compared to controls. CEA, acetabular abduction and acetabular anteversion were found to be mostly determined (adjusted $R^{2}: 0.08-0.32$ ) by pelvic tilt and less by frontal pelvic obliquity, frontal Cobb and T1T12.

Conclusions Subjects with AIS had a more abducted acetabulum at the lowered side, more anteverted acetabulum and a lack of anterior coverage of both acetabula. These alterations were strongly related to pelvic tilt.
\end{abstract}

Keywords Adolescent idiopathic scoliosis $\cdot$ Acetabulum $\cdot$ Lower limbs $\cdot$ 3D reconstructions $\cdot$ Spine

\section{Introduction}

The 3D deformity of the spine in adolescent idiopathic scoliosis (AIS) causes alterations in posture, spino-pelvic sagittal alignment [1] and pelvic orientation [2]. The pelvic vertebra, as described by Dubousset [3], is often an integral part of the scoliotic curvature, and any spino-pelvic deformity could

Ayman Assi

ayman.assi@gmail.com; ayman.assi@usj.edu.lb

1 Laboratory of Biomechanics and Medical Imaging, Faculty of Medicine, University of Saint-Joseph in Beirut, Beirut, Lebanon

2 Bordeaux University Hospital, Bordeaux, France

3 Institut de Biomécanique Humaine Georges Charpak, Arts et Métiers ParisTech, Paris, France cause its tilting in the frontal and sagittal planes, and its rotation in the axial plane.

Previous studies on subjects with AIS found acetabular and lower limbs alterations, such as decreased femoral torsion [4], a greater neck-shaft angle [5], differences in femur lengths, total lower limbs lengths and tibial torsions between sides of subjects with AIS [6]; these findings were attributed to spino-pelvic alterations. However, these studies remain scarce, and a comprehensive analysis of the relationship between the spino-pelvic deformity in AIS and acetabular and lower limb morphological alterations is lacking, especially since these alterations were shown to be related to the development of pathologies of the hip such as osteoarthritis [7].

Thus, the aim of this study was to investigate changes in the morphology of the acetabulum and lower limbs between 
subjects with AIS and controls, and to elucidate the relationship between the $3 \mathrm{D}$ deformities of the spine and the acetabula.

\section{Methods}

\section{Subjects and imaging}

This is an IRB approved retrospective descriptive study (CEHDF742) on non-operated subjects with AIS who had consulted our center for imaging. Demographics (age, weight and height) were collected for each subject. All subjects underwent full-body biplanar radiographs (EOS Imaging $^{\circledR}$, Paris, France). Subjects were asked to stand in a modified free-standing position [8], and acquisitions were performed by a qualified technician.

Inclusion criteria were: age between 10 and 18 years old, diagnosed with AIS, with a frontal Cobb angle $\geq 10^{\circ}$. The exclusion criterion was the presence of structural lower limb discrepancy $>1 \mathrm{~cm}$ (measured from the center of the femoral head to the middle distal tibial end). A control group of asymptomatic subjects, recruited for a previous study, with no musculoskeletal or neurological disorders, were included.
Neither group reported any pain or pathologies related to the hips or lower limbs.

The spine and lower limbs of each subject were reconstructed in 3D by well-trained operators using SterEOS ${ }^{\circledR}$ (version 1.6.4.7977, EOS imaging, Paris), as well as the pelvises and the acetabula using a specific software (Arts et Métiers ParisTech, Paris, France).

\section{Collected parameters}

Different 3D spino-pelvic, acetabular and lower limb parameters were collected from the 3D reconstructions (Fig. 1) [9]. The spino-pelvic parameters included: frontal Cobb angle, type of curvature according to Lenke [10], apical vertebral rotation (AVR), T1T12 kyphosis, L1S1 lordosis, pelvic incidence (PI), pelvic tilt (PT), lateral pelvic obliquity (LPA) (distance between iliac crests calculated in the frontal plane) and pelvic axial rotation (PAR) (in the horizontal plane). Spino-pelvic parameters were calculated in the $3 \mathrm{D}$ patient plane. Global postural parameters were also collected: sagittal vertical axis (SVA: as the distance from the C7 plumbline to the posterior corner of the sacrum), CAM-HA plumbline (as the distance from the plumbline passing by the center of auditory meatus to the center of the hip axis), T1 and T9 tilt

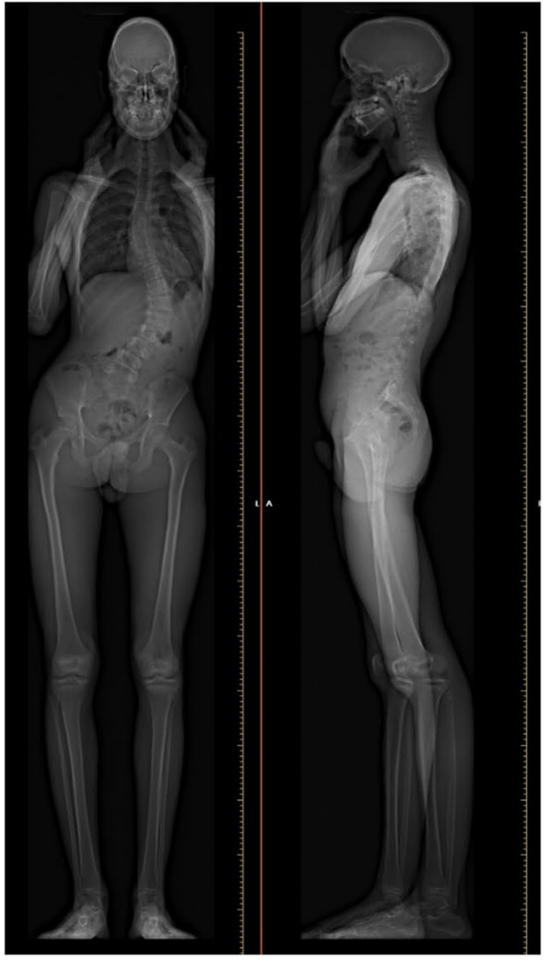

a

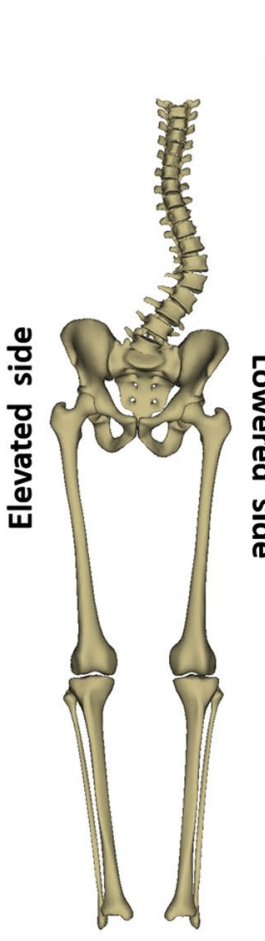

b
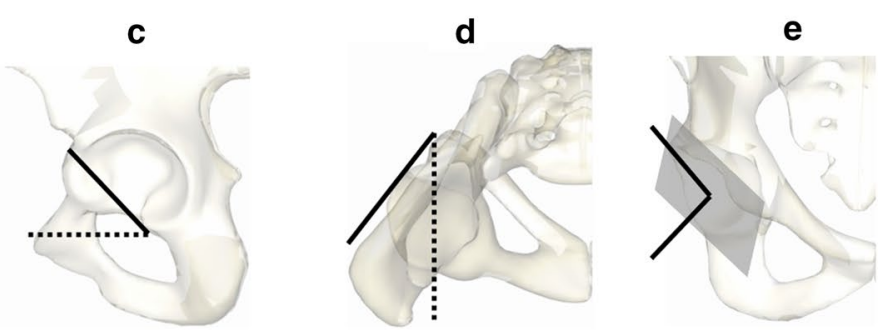

$\frac{5}{5}$

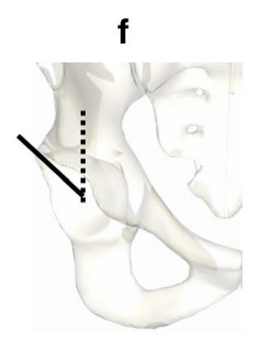

h

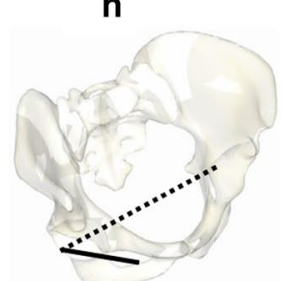

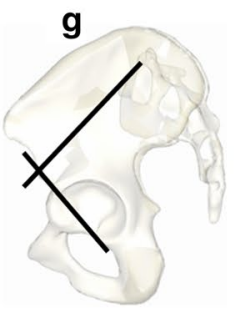

i

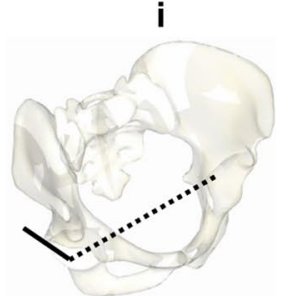

Fig. 1 a Full-body biplanar X-rays for a patient with adolescent idiopathic scoliosis, $\mathbf{b}$ 3D reconstructions of the spine, pelvis and lower limbs with classification of elevated and lowered sides, $\mathbf{c}$ acetabular

tilt, $\mathbf{d}$ acetabular anteversion, $\mathbf{e}$ acetabular abduction, $\mathbf{f}$ center-edge angle, $\mathbf{g}$ sacro-acetabular angle, $\mathbf{h}$ anterior sector angle and $\mathbf{i}$ posterior sector angle 
and C7CSL (the distance from the center of $\mathrm{C} 7$ plumbline to the center of the sacral plate in the frontal plane).

The collected 3D acetabular parameters were: acetabular tilt [11], acetabular anteversion, acetabular abduction [12], center-edge angle (CEA) [13], anterior and posterior sector angles [14] and sacro-acetabular angle (SA) [11]. Acetabular anteversion and abduction were calculated morphologically, i.e., in the Lewinnek plane $(M)$, and positionally $(P)$, i.e., in the horizontal or vertical planes (Fig. 1). The collected 3D lower limb parameters were: femoral torsion, hip-knee shaft angle (HKS), knee flexion-extension, neck-shaft angle (NSA), tibial torsion, valgus/varus of the knee (hip-knee angle: HKA) and the tibial mechanical angle [15]. The ratio of the femur length over the tibial length [16], as well as the anatomical (sum of the femoral and tibial lengths) and functional lengths (distance between the center of the femoral head to the center of the ankle) of the full lower limbs were also calculated and normalized to height.

The validity and reliability of the aforementioned parameters have already been studied [17, 18].

\section{Statistical analysis}

Mean differences between AIS and controls for demographic data were tested using either Mann-Whitney's $U$ test or a two-sample $t$-test depending on data normality (Shapiro-Wilk's test).

The two limbs were included for each subject with AIS and grouped according to the pelvic obliquity in the frontal plane (obtained from the 3D reconstruction) into elevated side (ES) and lowered side (LS). Acetabular, lower limb and 3D length parameters were first compared between each side of AIS (ES or LS) using either a paired t-test or Wilcoxon signed rank test. For the control group, the left and right sides were averaged after confirmation of no statistical differences between both sides. Then, each side of the AIS was compared to controls using a Mann-Whitney's $U$ test or a two-sample $t$-test.

Differences between groups were also investigated by studying the distribution of the parameters: CEA, NSA and acetabular anteversion were compared between groups according to specific ranges used in clinical classifications (CEA for risk of overcoverage or dysplasia; NSA and acetabular anteversion for risk of femoro-acetabular impingement) $[13,19,20]$. When no clinical classifications were found in the literature, the control group was divided into 3 classes, which were defined as: low, if inferior than mean-1 SD (17\% of subjects); intermediate, if it falls between mean and $1 \mathrm{SD}$ and mean +1 SD ( $66 \%$ of subjects); high, if superior than mean +1 SD (17\% of subjects). The distribution of the AIS sides was then evaluated based on these classifications. Heterogeneity was assessed using a Chi-squared test; pairwise comparisons were computed using adjusted residuals.
In order to investigate the relationship between the 3D acetabular and lower limbs parameters that differed between groups and spino-pelvic parameters, a univariate analysis using Pearson's correlation test was applied. Then, in order to explore the most significant determinants of the acetabular and lower limb 3D parameters among demographics and spino-pelvic parameters, a multivariate analysis using stepwise multiple linear regression was computed.

Statistics were performed using Xlstat ${ }^{\circledR}$ (version 2019.1.2, Addinsoft $^{\circledR}$, Paris, France). The level of significance was set at 0.05 .

\section{Results}

\section{Study sample}

In total, 274 subjects with AIS were included in this study (232 females, age: $14.4 \pm 2$ years). Frontal Cobb angle and AVR were $33.5^{\circ} \pm 18^{\circ}\left[10^{\circ}-110^{\circ}\right]$ and $14.3^{\circ} \pm 9^{\circ}\left[0.1^{\circ}-39^{\circ}\right]$, respectively. Subjects with AIS were classified as follow: 128 Lenke type-1, 8 Lenke type-2, 8 Lenke type-3, 119 Lenke type-5 and 11 Lenke type-6; there were no subjects with Lenke type-4. Lower limb discrepancy had a median of $0.3 \mathrm{~cm}[0-0.9 \mathrm{~cm}]$. In total, 84 asymptomatic subjects were also included in the control group (60 females, age: $14.1 \pm 3.1$ years). There were no significant differences between AIS and controls in demographic data (all $p>0.05$, Table 1).

Mean values of the spino-pelvic and postural parameters were compared between groups (Fig. 2). Briefly, T1T12 and CAM-HA were significantly lower in subjects with AIS $\left(33.6^{\circ} \pm 12^{\circ},-27.5 \pm 23 \mathrm{~mm}\right.$, respectively) when compared to controls $\left(42.7^{\circ} \pm 8^{\circ},-19.9 \pm 24 \mathrm{~mm}\right.$, respectively). Lateral pelvic obliquity and C7CSL were significantly higher in subjects with AIS $(5.3 \pm 3.5 \mathrm{~mm}, 11.5 \pm 9 \mathrm{~mm}$, respectively) when compared to controls $(4 \pm 3.5 \mathrm{~mm}, 7.8 \pm 6 \mathrm{~mm}$, respectively).

The detailed comparison of acetabular and lower limb parameters between the ES, LS in AIS and controls were presented in Table 2. Acetabular abduction $(M$ and $P$ ) were significantly higher in the ES group $\left(59.2^{\circ} \pm 6^{\circ}, 56.6^{\circ} \pm 4^{\circ}\right.$, respectively) when compared to both $\operatorname{LS}\left(55.6^{\circ} \pm 6^{\circ}\right.$,

Table 1 Comparison of demographics between controls and adolescent idiopathic scoliosis (AIS)

\begin{tabular}{|c|c|c|c|c|c|}
\hline \multirow[t]{2}{*}{ Demographics } & \multicolumn{2}{|c|}{ Control } & \multicolumn{2}{|l|}{ AIS } & \multirow[t]{2}{*}{$p$ value } \\
\hline & Mean & SD & Mean & $\mathrm{SD}$ & \\
\hline Age (years) & 14.1 & 3.1 & 14.4 & 2.0 & 0.06 \\
\hline Weight (kg) & 52.0 & 14.8 & 52.3 & 11.4 & 0.37 \\
\hline Height (m) & 1.6 & 0.1 & 1.6 & 0.1 & 0.06 \\
\hline
\end{tabular}




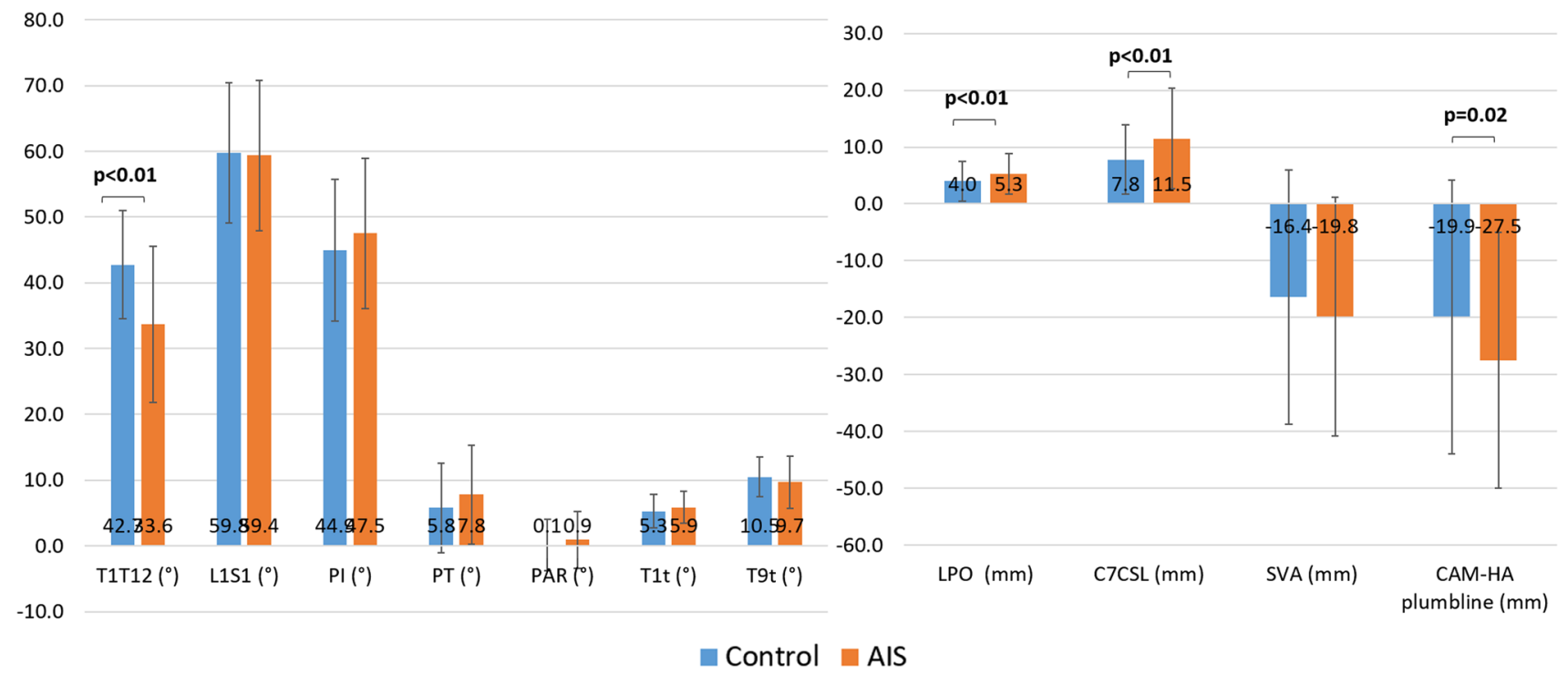

Fig. 2 Comparison of 3D spino-pelvic parameters between AIS and controls. T1T12 kyphosis (T1T12), L1S1 lordosis (L1S1), pelvic incidence (PI), pelvic tilt (PT), pelvic axial rotation (PAR), T1

tilt (T1t), T9 tilt (T9t), lateral pelvic obliquity (LPO), C7CSL frontal plumbline (C7CSL), sagittal vertical axis (SVA) and CAM-HA plumbline (CAM-HA)

Table 2 Between-group comparisons of 3D acetabular and lower limbs parameters in controls, elevated side (ES) and lowered side (LS) of subjects with adolescent idiopathic scoliosis

\begin{tabular}{|c|c|c|c|c|c|c|c|c|c|}
\hline \multirow[t]{2}{*}{ Parameters } & \multicolumn{2}{|l|}{ Control } & \multicolumn{2}{|c|}{$\begin{array}{l}\text { Elevated side } \\
\text { (ES)- AIS }\end{array}$} & \multicolumn{2}{|c|}{$\begin{array}{l}\text { Lowered side } \\
\text { (LS)- AIS }\end{array}$} & \multirow{2}{*}{$\begin{array}{l}\text { Control versus ES } \\
p \text { value }\end{array}$} & \multirow{2}{*}{$\begin{array}{l}\text { Control versus LS } \\
p \text { value }\end{array}$} & \multirow{2}{*}{$\begin{array}{l}\text { ES versus LS } \\
p \text { value }\end{array}$} \\
\hline & Mean & SD & Mean & SD & Mean & SD & & & \\
\hline Acetabular abduction $M\left(^{\circ}\right)$ & 57.5 & 3.9 & 59.2 & 6.0 & 55.6 & 6 & 0.01 & 0.005 & $<0.001$ \\
\hline Acetabular abduction $P\left(^{\circ}\right)$ & 55.5 & 3.8 & 56.6 & 4.2 & 53.9 & 4.2 & 0.04 & 0.001 & $<0.001$ \\
\hline Acetabular tilt angle $\left(^{\circ}\right)$ & 20.6 & 6.3 & 21.6 & 8.1 & 21.3 & 7.8 & 0.27 & 0.44 & 0.64 \\
\hline Center-edge angle $\left(^{\circ}\right)$ & 29.8 & 4.8 & 28.7 & 5.1 & 32 & 6.1 & 0.10 & 0.005 & $<0.001$ \\
\hline Sacro-acetabular angle $\left({ }^{\circ}\right)$ & 56.6 & 9.9 & 60.4 & 12.0 & 60 & 12.6 & 0.01 & $\mathbf{0 . 0 3}$ & 0.53 \\
\hline Acetabular anteversion $M\left(^{\circ}\right)$ & 19.1 & 4 & 19.8 & 5.1 & 20.5 & 5.7 & 0.21 & $\mathbf{0 . 0 3}$ & $\mathbf{0 . 0 3}$ \\
\hline Acetabular anteversion $P\left({ }^{\circ}\right)$ & 14.8 & 3.9 & 15.5 & 4.5 & 15.9 & 5 & 0.16 & 0.02 & 0.18 \\
\hline Anterior sector angle $\left(^{\circ}\right)$ & 61 & 4.4 & 59.1 & 6.1 & 59.2 & 6.5 & 0.01 & $\mathbf{0 . 0 3}$ & 0.84 \\
\hline Posterior sector angle $\left(^{\circ}\right)$ & 94.2 & 4.4 & 94.7 & 5.5 & 94.2 & 5.9 & 0.44 & 0.66 & 0.30 \\
\hline Femoral mechanical angle $\left(^{\circ}\right)$ & 93.9 & 1.5 & 94.1 & 1.9 & 93.9 & 2 & 0.31 & 0.98 & 0.05 \\
\hline Femoral torsion $\left(^{\circ}\right)$ & 16.7 & 9.6 & 16.9 & 10.9 & 17.5 & 11.1 & 0.79 & 0.43 & 0.22 \\
\hline Hip-knee shaft angle $\left(^{\circ}\right)$ & 4 & 0.8 & 4.2 & 1.1 & 4.3 & 1 & 0.25 & 0.04 & 0.14 \\
\hline Knee flexion-extension $\left(^{\circ}\right)$ & -3.1 & 5 & -2.4 & 5.4 & -3.4 & 5.3 & 0.27 & 0.72 & $<0.001$ \\
\hline Neck-shaft angle $\left(^{\circ}\right)$ & 131.4 & 4.3 & 130.8 & 4.6 & 130.6 & 4.4 & 0.27 & 0.14 & 0.38 \\
\hline Tibial torsion $\left(^{\circ}\right)$ & 28.5 & 6.6 & 28.6 & 7.2 & 29.3 & 7.1 & 0.88 & 0.37 & 0.11 \\
\hline Valgus/varus $\left({ }^{\circ}\right)$ & 0.4 & 2.2 & 0.5 & 2.6 & 0.3 & 2.8 & 0.86 & 0.76 & 0.22 \\
\hline Tibial mechanical angle $\left(^{\circ}\right)$ & 89.1 & 2.4 & 89.3 & 2.9 & 89.8 & 2.8 & 0.67 & 0.05 & $<0.001$ \\
\hline Ratio of femur length over tibia length & 1.16 & 0.03 & 1.16 & 0.03 & 1.16 & 0.03 & 0.24 & 0.11 & 0.98 \\
\hline Anatomical length (cm) & 74.5 & 6.2 & 76.4 & 4.3 & 76.2 & 4.3 & 0.002 & 0.01 & $<0.001$ \\
\hline Normalized anatomical length & 0.471 & 0.01 & 0.475 & 0.02 & 0.474 & 0.02 & 0.01 & 0.09 & $<0.001$ \\
\hline Functional length $(\mathrm{cm})$ & 74.9 & 6.2 & 76.8 & 4.3 & 76.6 & 4.3 & 0.002 & 0.01 & $<0.001$ \\
\hline Normalized functional length & 0.474 & 0.01 & 0.478 & 0.02 & 0.477 & 0.02 & 0.01 & 0.10 & $<0.001$ \\
\hline
\end{tabular}

Significant $p$ values are indicated in bold 
$53.9^{\circ} \pm 4^{\circ}$, respectively) and controls $\left(57.5^{\circ} \pm 4^{\circ}, 55.5^{\circ} \pm 4^{\circ}\right.$, respectively). CEA and acetabular anteversion ( $M$ and $P$ ) were significantly higher in the LS $\left(32^{\circ} \pm 6^{\circ}, 20.5^{\circ} \pm 6^{\circ}\right.$, $15.9^{\circ} \pm 5^{\circ}$, respectively) group when compared to both ES $\left(28.7^{\circ} \pm 5^{\circ}, 19.8^{\circ} \pm 5^{\circ}, 15.5^{\circ} \pm 4.5^{\circ}\right.$, respectively) and controls $\left(29.8^{\circ} \pm 5^{\circ}, 19.1^{\circ} \pm 4^{\circ}, 14.8^{\circ} \pm 4^{\circ}\right.$, respectively). The anterior sector angle was significantly lower in both ES $\left(59.1^{\circ} \pm 6^{\circ}\right)$ and $\operatorname{LS}\left(59.2^{\circ} \pm 6.5^{\circ}\right)$ groups when compared to controls $\left(61^{\circ} \pm 4^{\circ}\right)$. Femoral torsion, NSA, tibial torsion and valgus/varus did not differ between groups. The ratio of the femoral length over the tibia length ranged between 1.1 and 1.2 and was similar between groups. Both normalized anatomical and functional lengths were significantly higher in the ES $(0.475 \pm 0.02,0.478 \pm 0.02$, respectively) while compared to both LS in AIS $(0.474 \pm 0.02,0.477 \pm 0.02$, respectively) and controls $(0.471 \pm 0.01,0.474 \pm 0.01$, respectively).

\section{Distributions of 3D acetabular parameters}

When the CEA was evaluated based on the clinical ranges published by Tannast [20], the ES group tended toward dysplasia and the LS group was significantly shifted toward overcoverage (Fig. 4). Acetabular anteversion and NSA were similar to normal ranges when assessing the risk of femoro-acetabular impingement based on the clinical classifications published in the literature $[13,19]$.

When the distribution of the ES and LS groups were compared to controls for both the morphological and positional acetabular abduction, the LS group tended toward the low class and the ES to the high class of controls (Fig. 3). For the anterior sector angle, morphological and positional acetabular anteversion, both ES and LS groups tended toward the low class of controls (Figs. 3, 4). For the posterior sector angle and SA angle, both ES and LS groups tended toward the high class of controls (Fig. 4).

\section{Univariate analysis}

CEA was significantly correlated to: age $(r=-0.20$, $p=0.05)$, T1 tilt $(r=-0.25, p=0.01)$ and PT $(r=-0.25$, $p=0.01)$. Positional acetabular abduction was significantly correlated to: T1 tilt $(r=0.23, p=0.02)$, T9 tilt $(r=0.25$, $p=0.01)$, SS $(r=-0.20, p=0.04)$ and PT $(r=0.32$, $p=0.001$ ) (Fig. 5). Positional acetabular anteversion was significantly correlated to CAM-HA plumbline $(r=-0.36$, $p<0.01)$, T1 tilt $(r=0.30, p=0.002)$, PI $(r=0.41$, $p<0.001)$ and PT $(r=0.45, p<0.001)$ (Fig. 5).
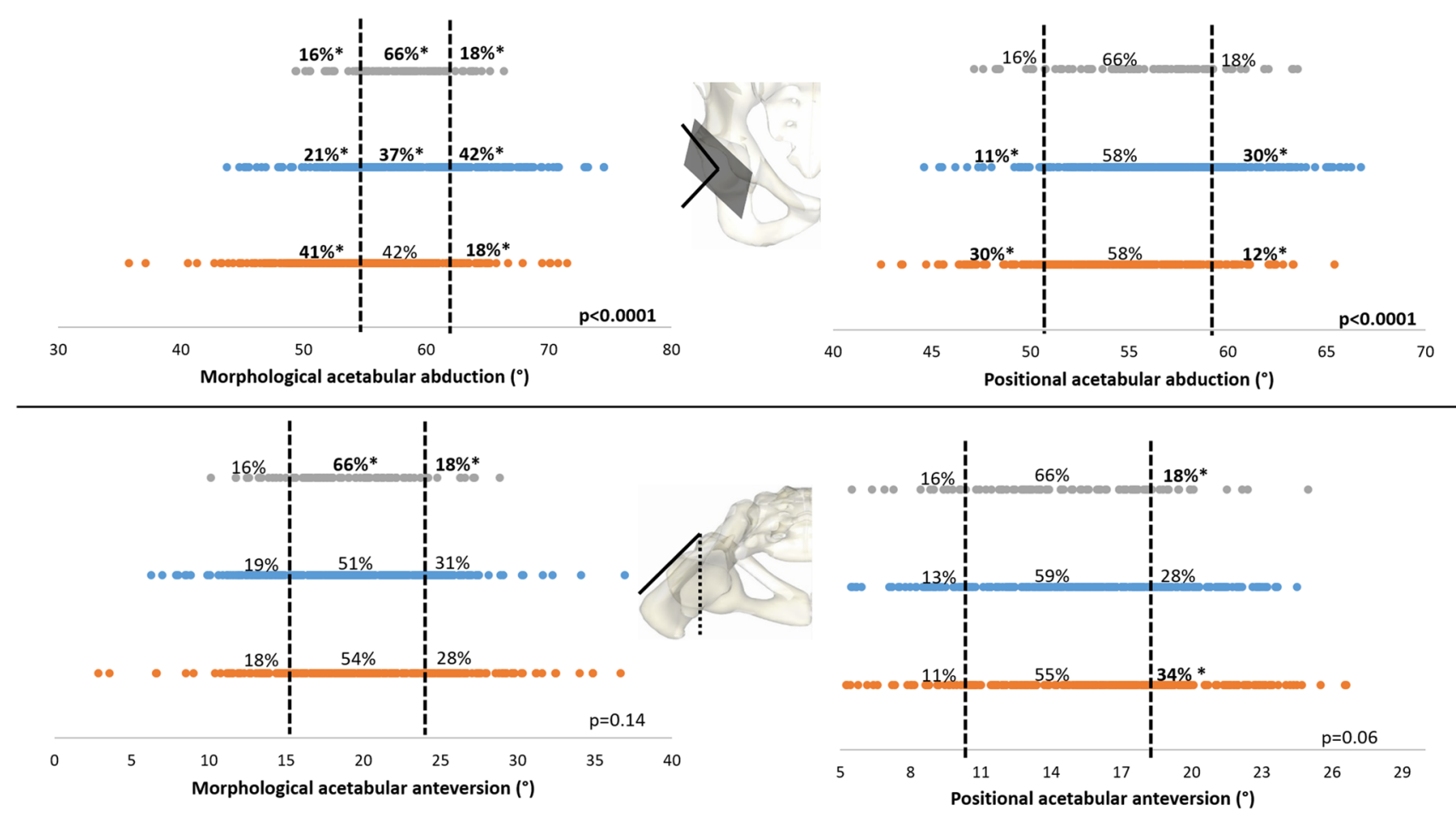

- AIS elevated side - AIS lowered side c Control mean

Fig. 3 Distribution of morphological and positional acetabular abduction and anteversion according to the normative classes (low, intermediate and high) as defined by the control group. ${ }^{*} p$ value $>0.05$ 


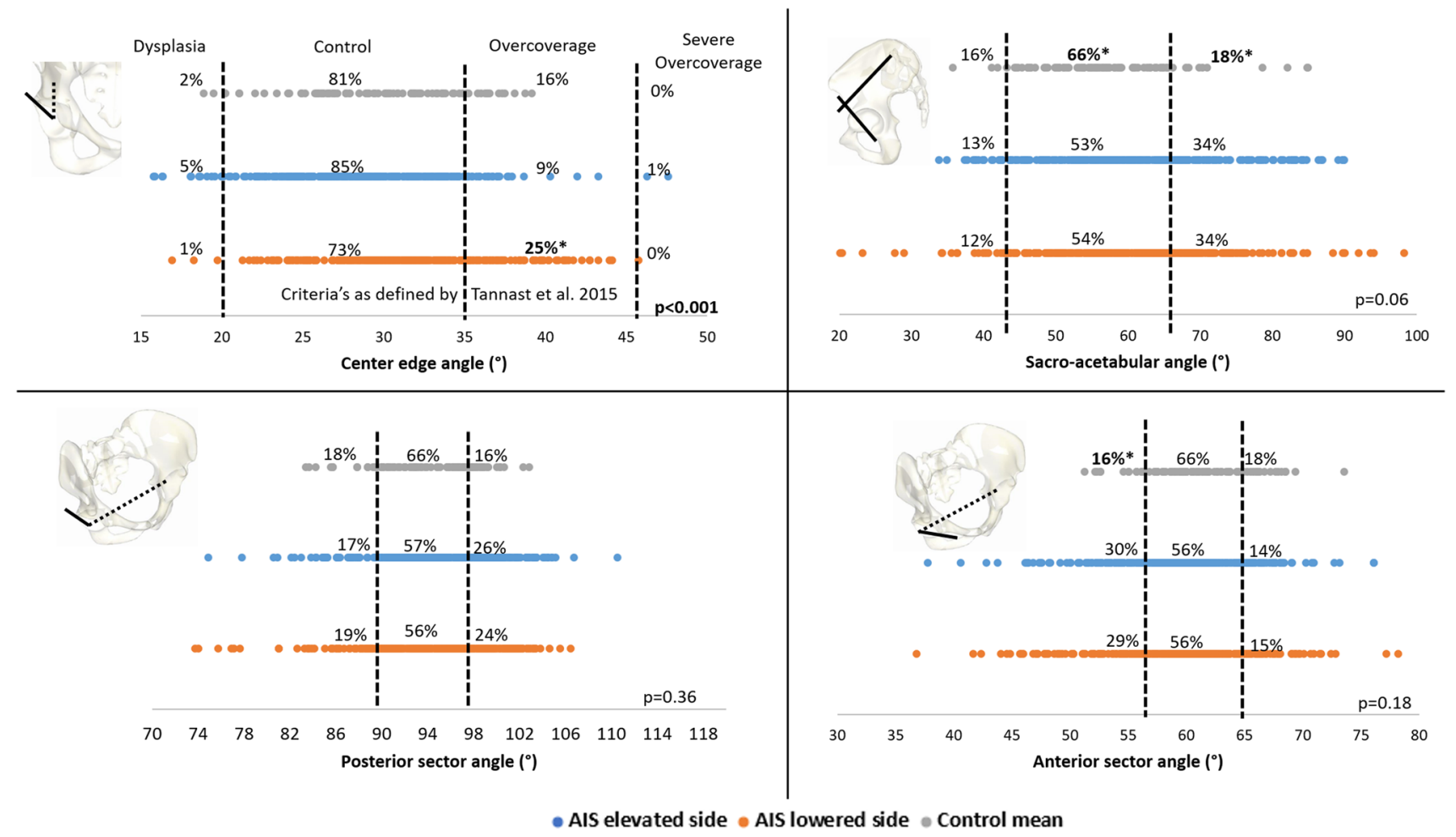

Fig. 4 Distribution of center-edge angle according to the criteria's as defined by Tannast et al. 2005. In addition to the distribution of sacroacetabular angle, posterior and anterior sector angles according to the normative classes (low, intermediate and high) as defined by the control group. ${ }^{*} p$ value $>0.05$
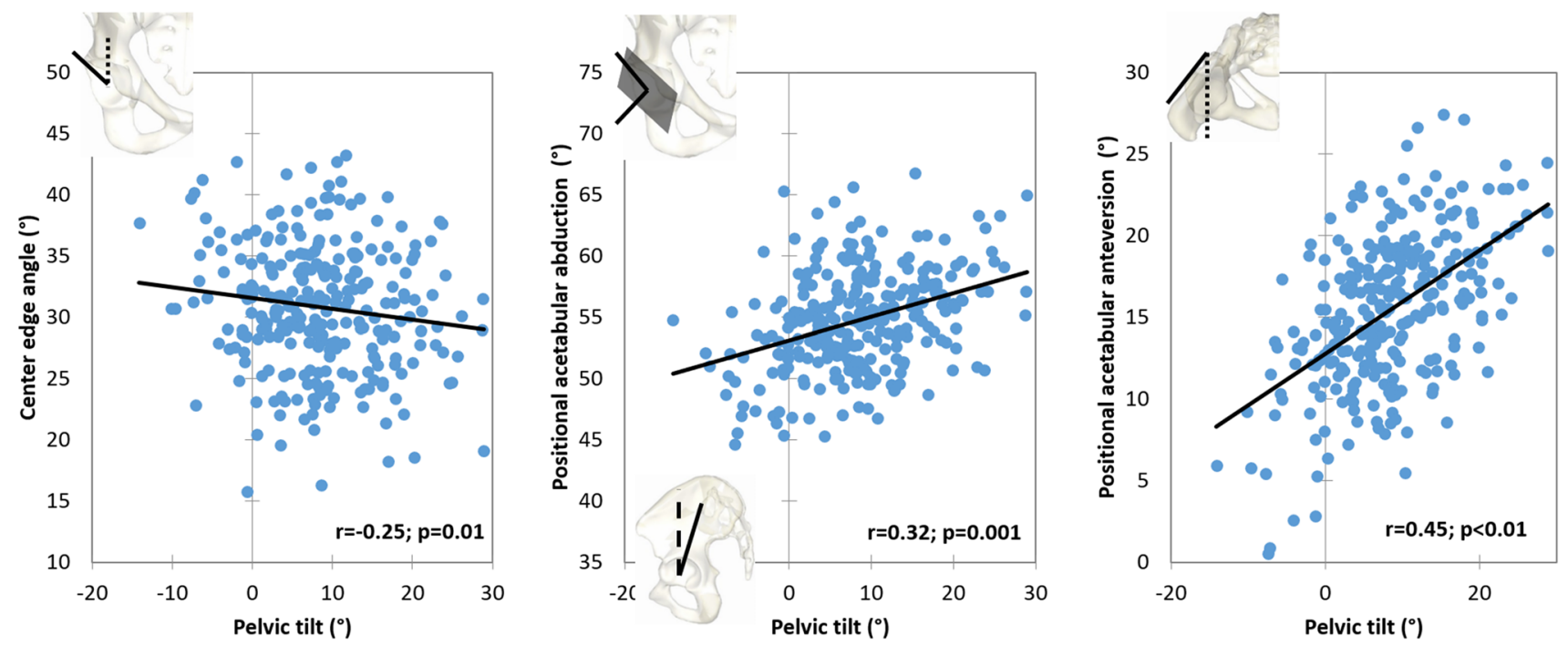

Fig. 5 Correlations between center-edge angle, positional acetabular abduction, positional acetabular anteversion and pelvic tilt

\section{Multivariate analysis}

CEA was determined (adjusted $R^{2}=0.08$ ) by PT $(\beta=-0.08 ; p=0.003)$. Positional acetabular abduction was determined (adjusted $\left.R^{2}=0.19\right)$ by PT $(\beta=0.32 ; p<0.001)$ and lateral pelvic obliquity $(\beta=0.07 ; p=0.03)$. Positional acetabular anteversion was determined (adjusted $R^{2}=0.32$ ) by frontal Cobb angle $(\beta=0.18, p<0.001)$, T1T12 kyphosis $(\beta=0.07, p=0.04)$ and PT $(\beta=0.51, p<0.001)$. 


\section{Discussion}

Adolescent idiopathic scoliosis (AIS) is known to alter the orientation of the pelvis in the 3 planes, which may lead to alterations in acetabular and lower limb morphologies. This study investigated the changes that might occur in acetabular and lower limb morphologies in these subjects while analyzing both the elevated and lowered sides of the pelvis as well as their correlation to the spino-pelvic parameters. Subjects with AIS had a more abducted acetabulum at the lowered side, more anteverted acetabulum and a lack of anterior coverage of both acetabula. These alterations were strongly related to pelvic tilt.

The spino-pelvic and global posture alterations found in the AIS group were similar to those reported in previous studies [21]. The analysis of acetabular and lower limb parameters between both sides of AIS and controls showed some morphological and positional alterations. Along with the comparisons of means of acetabular and lower limb parameters between both sides of AIS and controls, a comparison of the distributions of these parameters has also been investigated. This type of study allowed for a more thorough analysis of the heterogeneous anatomy of subjects with AIS and differences with previously published clinical ranges or normative data.

CEA and acetabular abduction are frequently used in the assessment of the acetabular coverage. These parameters are inversely related: when the CEA increases, the acetabular abduction decreases, and vice versa. According to the clinical ranges of CEA published by Tannast et al. [20] (Fig. 4), it was found that the LS of subjects with AIS is significantly more shifted toward overcoverage than the ES and controls and the positional acetabular abduction to be significantly more shifted toward the higher class of controls (Fig. 3); in contrary, the ES were more shifted toward dysplasia ranges for the CEA and to the lower class of controls for the positional acetabular abduction. Since the positional acetabular abduction was significantly determined by the position of the pelvis in both the frontal and sagittal planes, the frontal obliquity might have moved the lateral edge of the acetabulum on the LS externally, which might lead to a lower acetabular abduction, and consequently to a higher external coverage of the femoral head. The opposite effect takes place on the ES, showing more subjects having undercoverage compared to controls. Our findings, based on 3D data, are in disagreement with Schmitz et al. [22], who, by grouping both acetabula together, found no differences while comparing the CEA, calculated in 2D, of AIS subjects to controls. It is therefore interesting to consider each side separately when analyzing the acetabula of subjects with AIS.

When analyzing the anterior sector angle, the ES and LS hips were shifted toward the low class in controls
(Fig. 4), thus indicating a high prevalence of decreased anterior femoral head coverage in subjects with AIS in both hips (ES and LS). Moreover, positional acetabular anteversion in both sides of AIS pelvis was significantly more shifted toward the high class of controls (Fig. 3). This increase in acetabular anteversion was also present morphologically. Both the increase of acetabular anteversion and the decrease of the anterior sector angle show that subjects with AIS have a more exposed femoral head anteriorly on both the ES and LS that could predispose them to hip dysplasia. These findings are in accordance with previous study showing that subjects with AIS have a higher incidence of dysplasia compared to normal population [23].

Moreover, acetabular anteversion and acetabular abduction were both positionally and morphologically significantly different between groups (Table 2), this might show that subjects with AIS have already morphological alterations of the acetabula in addition to the positional impact of the spinal deformity on the acetabula.

The alterations of the CEA, acetabular abduction and anteversion were found to be correlated (Fig. 5) and mostly determined by PT ( $\beta=-0.08, \beta=0.32$ and $\beta=0.51$, respectively) showing that the alteration of the position of the pelvis in the sagittal plane have a major impact on the acetabular coverage over the femoral head as shown in a previous study [24].

Surgical spinal realignment of subjects with adult spinal deformity showed that improving the sagittal alignment by increasing the lumbar lordosis had consequently decreased the pelvic tilt and acetabular anteversion [25]. In this study, the acetabular anteversion, abduction and CEA were correlated and determined by the pelvic tilt; this might highlight the importance of the continuous monitoring of the sagittal alignment of subjects with AIS since they might be at risk of developing acetabular alteration in case they did not reach the proper sagittal alignment.

Differences in spino-pelvic parameters in patients with spinal pathologies and on patients with hip osteoarthritis have been extensively studied before. Moreover, many studies have explored the relationship between hip and spine pathologies, especially in the adult setting. This is a descriptive study of the changes that occurs in the acetabular orientation and lower limb morphology in subjects with AIS. The major limitation of this study is its retrospective nature and that the included patients were not followed up in order to confirm whether they later developed hip pathologies, although such a task might require the observation of these subjects for many years into the future. A prospective study is developed in order to follow up these patients.

In conclusion, subjects with AIS were found to have significant asymmetry in hip morphology leading to a more abducted acetabulum on the LS and a more anterior 
undercoverage as well as anteverted acetabula on both sides. These alterations were essentially correlated and determined by the pelvic tilt in the sagittal plane.

Acknowledgments This research was funded by the University of Saint-Joseph (grant FM300). The funding source did not intervene in study design; in the collection, analysis and interpretation of data; in the writing of the report; and in the decision to submit the article for publication.

Funding This study was funded by the University of Saint-Joseph (Grant No. FM300).

\section{Compliance with ethical standards}

Conflict of interest The authors declare that they have no conflict of interest.

\section{References}

1. Alzakri A, Vergari C, Van den Abbeele M et al (2019) Global sagittal alignment and proximal junctional kyphosis in adolescent idiopathic scoliosis. Spine Deform 7:236-244. https://doi. org/10.1016/j.jspd.2018.06.014

2. Pasha S, Aubin C-E, Sangole AP et al (2014) Three-dimensional spinopelvic relative alignment in adolescent idiopathic scoliosis. Spine (Phila Pa 1976) 39:564-570. https://doi.org/10.1097/ brs.0000000000000193

3. Dubousset J (1990) CD instrumentation in pelvic tilt. Orthopade 19:300-308

4. Burwell RG, Aujla RK, Kirby AS et al (2008) Ultrasound femoral anteversion (FAV) and tibial torsion (TT) after school screening for adolescent idiopathic scoliosis (AIS). Stud Health Technol Inform 140:225-230

5. Saji MJ, Upadhyay SS, Leong JC (1995) Increased femoral neckshaft angles in adolescent idiopathic scoliosis. Spine (Phila Pa 1976) 20:303-311

6. Márkus I, Schlégl ÁT, Burkus M et al (2018) The effect of coronal decompensation on the biomechanical parameters in lower limbs in adolescent idiopathic scoliosis. Rev Chir Orthop Traumatol 104:441. https://doi.org/10.1016/j.rcot.2018.06.018

7. Lazennec J-Y, Brusson A, Rousseau M-A (2011) Hip-spine relations and sagittal balance clinical consequences. Eur Spine $\mathrm{J}$ 20:1-13. https://doi.org/10.1007/s00586-011-1937-9

8. Chaibi Y, Cresson T, Aubert B et al (2012) Fast 3D reconstruction of the lower limb using a parametric model and statistical inferences and clinical measurements calculation from biplanar X-rays. Comput Methods Biomech Biomed Eng 15:457-466. https://doi. org/10.1080/10255842.2010.540758

9. Massaad A, Assi A, Bakouny Z et al (2016) Three-dimensional evaluation of skeletal deformities of the pelvis and lower limbs in ambulant children with cerebral palsy. Gait Posture. https://doi. org/10.1016/j.gaitpost.2016.06.029

10. Lenke LG, Betz RR, Harms J et al (2001) Adolescent idiopathic scoliosis: a new classification to determine extent of spinal arthrodesis. J Bone Joint Surg Am 83:1169-1181

11. Lazennec J-Y, Charlot N, Gorin M et al (2004) Hip-spine relationship: a radio-anatomical study for optimization in acetabular cup positioning. Surg Radiol Anat 26:136-144. https://doi. org/10.1007/s00276-003-0195-x
12. Anda S, Svenningsen S, Grontvedt T, Benum P (1990) Pelvic inclination and spatial orientation of the acetabulum. A radiographic, computed tomographic and clinical investigation. Acta Radiol 31:389-394

13. Tönnis D, Heinecke A (1999) Acetabular and femoral anteversion: relationship with osteoarthritis of the hip. J Bone Joint Surg Am 81:1747-1770. https://doi.org/10.2106/JBJS.L.00710

14. Anda S, Svenningsen S, Dale LG, Benum P (1986) The acetabular sector angle of the adult hip determined by computed tomography. Acta Radiol Diagn (Stockh) 27:443-447

15. Assi A, Presedo A, Baudoin A et al (2012) Specific 3D reconstruction for children lower limbs using a low dose biplanar X-ray system. Reproducibility of clinical parameters for cerebral palsy patients. Comput Methods Biomech Biomed Eng. https://doi. org/10.1080/10255840701479065

16. Rampal V, Rohan P-Y, Assi A et al (2018) Lower-limb lengths and angles in children older than six years: reliability and reference values by $\operatorname{EOS}^{\circledR}$ stereoradiography. Orthop Traumatol Surg Res 104:389-395. https://doi.org/10.1016/j.otsr.2017.10.007

17. Rehm J, Germann T, Akbar M et al (2017) 3D-modeling of the spine using EOS imaging system: inter-reader reproducibility and reliability. PLoS ONE 12:1-13. https://doi.org/10.1371/journ al.pone. 0171258

18. Assi A, Chaibi Y, Presedo A et al (2013) Three-dimensional reconstructions for asymptomatic and cerebral palsy children's lower limbs using a biplanar X-ray system: a feasibility study. Eur J Radiol 82:2359-2364. https://doi.org/10.1016/J.EJRAD .2013 .07 .006

19. Stem ESE, O'Connor MIM, Kransdorf MJM et al (2006) Computed tomography analysis of acetabular anteversion and abduction. Skeletal Radiol 35:385-389. https://doi.org/10.1007/s0025 6-006-0086-4

20. Tannast M, Hanke MS, Zheng G et al (2015) What are the radiographic reference values for acetabular under- and overcoverage? Clin Orthop Relat Res. https://doi.org/10.1007/s1199 9-014-4038-3

21. Nault M, Allard P, Le Blanc R et al (2002) Relations between standing stability and body posture parameters in adolescent idiopathic scoliosis. Spine 27:1911-1917. https://doi.org/10.1097/01. BRS.0000025720.91214.DB

22. Schmitz MR, Bittersohl B, Zaps D et al (2013) Spectrum of radiographic femoroacetabular impingement morphology in adolescents and young adults: an EOS-based double-cohort study. J Bone Joint Surg Am 95:e90. https://doi.org/10.2106/ JBJS.L.01030

23. Segreto FA, Vasquez-Montes D, Brown AE et al (2018) Incidence, trends, and associated risks of developmental hip dysplasia in patients with Early Onset and Adolescent Idiopathic Scoliosis. J Orthop 15:874-877. https://doi.org/10.1016/j.jor.2018.08.015

24. Henebry A, Gaskill T (2013) The effect of pelvic tilt on radiographic markers of acetabular coverage. Am J Sports Med 41:2599-2603. https://doi.org/10.1177/0363546513500632

25. Buckland AJ, Vigdorchik J, Schwab FJ et al (2015) Acetabular anteversion changes due to spinal deformity correction: bridging the gap between hip and spine surgeons. J Bone Joint Surg Am 97:1913-1920. https://doi.org/10.2106/JBJS.O.00276 